\title{
BACTERIAL DIVERSITY OF THE PANJIN RED BEACH BASED ON HIGH-THROUGHPUT AND CULTURE-DEPENDENT METHODS
}

\author{
WeI, C. Y. ${ }^{1}-$ GAO, T. $^{1}-$ YUAN, Y. ${ }^{1}-$ LI, Y. Y. ${ }^{1}-$ WANG, L. L. ${ }^{1}$ LI, X. M. ${ }^{1}-$ YU, C. M. ${ }^{2 *}$ \\ MA, L. J. ${ }^{*}$ \\ ${ }^{1}$ College of Life Science, Shenyang Normal University, No. 253 Huanghe North Street, \\ Shenyang, Liaoning 110034, China \\ ${ }^{2}$ College of Agronomy, Shenyang Agricultural University, Shenyang 110161, China \\ *Corresponding authors \\ e-mail: yucuimei@163.com, malianju@163.com \\ (Received $6^{\text {th }}$ Sep 2019; accepted $15^{\text {th }}$ Nov 2019)
}

\begin{abstract}
There are in plenty of microbial resources in Panjin Red Beach, which is a unique wetland in Liaoning province. In this experiment, we investigated bacterial diversity and community in order to understand internal soil microbial community characteristics composition of the soil. Soil samples were collected in five different areas. The bacterial diversity and community were investigated using combined culture-dependent and culture-independent approaches (high-throughput sequencing technology). Through the high-throughput sequencing of the Panjin Red Beach soil, bacterial community turned out to be mainly composed of 13 phyla in the samples collected from the five studied areas, which were Tenericutes, Spirochaetae, Latescibacteria, Verrucomicrobia, Planctomycetes, Cyanobacteria, Actinobacteria, Gemmationadetes, Chloroflexi, Acidobacteria, Firmicutes, Bacteroidetes and Proteobacteria. By cultivable methods, 80 halophilic and alkalophilic bacteria were isolated, and 42 bacteria were selected to be identified by $16 \mathrm{~S}$ rDNA, and were determined to belong to nine genus and four phyla. Bacillus and Planococcus was the dominant genus. Accordingly, the bacterial diversity was rich in Panjin Red Beach. Moreover, the data gathered using high-throughput technology is far more accessible than culture-dependant methods.
\end{abstract}

Keywords: microbial resources, extreme environment, culture-independent, culture-dependent, bacterial diversity

\section{Introduction}

Extreme environmental microbes are groups of microbes which can grow and reproduce in the extreme regions. For example, thermophilic microbes growing in environments such as hot springs and craters (Stetter et al., 1990), cold-loving microbes growing in extreme cold regions such as the Antarctic, snowy mountains and deep oceans (Liu et al., 2001), acidophilic microorganisms growing in metal deposits, saline soils and sulfur-bearing hot springs (Olson et al., 2003; Zettler et al., 2002), halophilic bacteria growing saline-alkali soil, alkaline lake and ocean environment (Horikoshi, 1999; Margesin and Schinner, 2001; Shi et al., 2012). A broad-spectrum of salt- and alkali-tolerant, and even drought-resistant microbial species resources were found in saline-alkaline soil (Shi et al., 2012). Panjin Red Beach is a very rare shallow shoal, in which soil belongs to saline-alkaline type. Though the microorganisms in extreme environments of saline-alkaline soil has been reported in former researches (Rietz and Haynes, 2003; Zahran, 1997), an in-depth study on the microbial resources in Panjin Red Beach extreme saline-alkaline soils is particularly rare. Therefore, we investigated structure and diversity of soil microbial communities in Panjin Red Beach region. 
Not only the survival status of the microbes was understood in a given habitat under certain culture conditions, but also the new species resources were obtained with potential application value by the traditional cultivable method (Bever et al., 2012). However, diversity of microbial communities is affected by culture-dependent methods in laboratory due to some uncertain factors. Moreover, $0.001-15 \%$ of the microbes in the environment can be cultured by culture-dependent methods. For the microorganisms existing in extreme environments, a large number of them are not allowed to be cultured. The microbial information obtained by culture-dependent methods is greatly limited. Some researchers explored methods and techniques by DGGE, clone library and T-RFLP for microbial community structure, but not explain the composition, diversity and function of microbial communities (Theron et al., 2000; Vanwonterghem et al., 2014). High-throughput sequencing technology provides an efficient method for analyzing species composition and relative abundance of microbial communities in complex environments, which can directly sequencing 16S rRNA gene PCR products and simultaneously analyze hundreds of different samples (Chistoserdova, 2010; Rinke et al., 2013). At present, it has been widely used in studies on the structural diversity of microbial communities in ocean, soil, human intestinal tract and other samples (Herlemann et al., 2011; Xia et al., 2011; Passalacqua et al., 2009). Therefore, traditional culture methods combining with High-throughput sequencing technology can comprehensively reflect the diversity of soil microbial. At present, the study on the diversity of microbial resources in Panjin Red Beach mainly focused on the soil microbes in Suaeda salsa the roots and endophyte (Zhao et al., 2015; Tian et al., 2016). In the present study, we used traditional culture methods combining with Highthroughput sequencing technology to study the diversity of soil microbial in Panjin Red Beach.

\section{Materials and methods}

\section{Samples collection and analysis}

Soil samples were collected from Panjin Red Beach in Panjin city of Liaoning province, China in July and September, 2016. Samples collected from 0-15 cm depth soil by five dot collection methods were homogeneously mixed and placed in sterile PVC bag, respectively, at five representative plots selected in the test area. All treatments were conducted in triplicate at each plot. Soil samples were put into ice box and brought lab. Some of them were kept in $-80{ }^{\circ} \mathrm{C}$ and sent to Shanghai Majorbio Corporation (Shanghai, China) to analyze bacteria community structure by highthroughput sequencing. The microbial species richness was represented by the number of unique OTUs (16S rDNA). Chao and Shannon's diversity index were also calculated based on 16S rDNA for comparison of alpha-diversity.

The others were used to determine soil character and analyzed bacterial diversity by culture-dependent methods.

\section{Determination of soil pH and electric conductivity}

Soil samples were put into clean paper and dried in shade place at temperature. The dried samples screened by $1 \mathrm{~mm}$ net. Samples $(10 \mathrm{~g})$ were put into $50 \mathrm{~mL}$ bottle. After adding $25 \mathrm{~mL}$ distilled water, samples were violently vibrated 5 min on magnetic 
agitator and let stand for $1 \mathrm{~h}$. Then, $\mathrm{pH}$ was determined by $\mathrm{pH}$ meter. All samples were conducted in triplicate. All samples were conducted in triplicate.

Samples $(20 \mathrm{~g})$ adding $100 \mathrm{~mL}$ water $(1: 5 \mathrm{~m} / \mathrm{V})$ were vibrated $5 \mathrm{~min}$ at $20 \pm 1{ }^{\circ} \mathrm{C}$. The $30 \mathrm{~mL}$ extraction buffer was used to determine electric conductivity at $25 \pm 1^{\circ} \mathrm{C}$ by conductivity meter.

\section{Solid medium}

Beef extract $0.3 \%$, peptone $1 \%, \mathrm{NaCl} 1.5 \%$, agar $2 \%, \mathrm{pH} 9.0,121{ }^{\circ} \mathrm{C}$ autoclave steam sterilization 30 min (Shen et al., 2006).

\section{Isolation and purification of microorganisms}

Five studied areas samples (10 g) were gradient diluted with sterile saline, respectively. Different gradient bacterial suspension $\left(10^{-3}, 10^{-4}, 10^{-5}\right)$ were uniformly spread on the surface of solid isolation medium plate. Each dilution was conducted in triplicate. Aseptic water was used as control. All treatments were cultured 2 days at $37^{\circ} \mathrm{C}$ in incubator. According to clone morphology, different single clone was purified and inoculated in solid slope media for other treatments.

\section{Molecular identification of cultured bacteria}

The total genomic DNA of the cultured bacteria strain was extracted and purified using Bacterial DNA Isolation Kit (Sangon Biotech Co., Ltd, China) according to manufacturer's instructions. The $16 \mathrm{~S}$ rDNA of the isolate was amplified through PCR reaction using the universal primers 27f (5'-AGAGTTTGATCATCCTGGCTCAG-3') and 1492r (5'-TACGGTTACCTTGTTACGACTT-3') synthesized by Sangon Biotech Co., Ltd (Shanghai, China). PCR reactions were performed in $50 \mu \mathrm{L}$ mixture PCR reaction system containing $27 \mathrm{f}(10 \mu \mathrm{M})$ and $1492 \mathrm{r}(10 \mu \mathrm{M})$ primer $1 \mu \mathrm{L}$, respectively, DNA template $2 \mu \mathrm{L}, 2 \times$ Premix Taq $(5.0 \mathrm{U} / \mu \mathrm{L}) 25 \mu \mathrm{L}, \mathrm{ddH}_{2} \mathrm{O} 21 \mu \mathrm{L}$. PCR reaction condition was $95^{\circ} \mathrm{C} 5 \mathrm{~min}, 95^{\circ} \mathrm{C} 1 \mathrm{~min}, 55^{\circ} \mathrm{C} 1 \mathrm{~min}, 72{ }^{\circ} \mathrm{C} 2 \mathrm{~min}, 35$ cycles, $72{ }^{\circ} \mathrm{C}$ 10 min. PCR products were sent to Shanghai Sangon Biotech Co. Ltd to sequence. Homology comparison was conducted online in EzBioCloud database (https://www.ezbiocloud.net/).

\section{Results and discussion}

\section{Soil electric conductivity and $\mathrm{pH}$ value}

Soil electric conductivity and $\mathrm{pH}$ value reflected degree of soil saline-alkali. In five geographical regions studied, the highest $\mathrm{pH}$ value is 8.66 , and the lowest $\mathrm{pH}$ value is 8.09. The highest electric conductivity is $10.6 \mathrm{mS} / \mathrm{cm}$, and the lowest value is $3.65 \mathrm{mS} / \mathrm{cm}$ (Table 1). These data showed that the soil of five geographical regions studied is saline-alkali soil.

Table 1. Soil electric conductivity and $p H$ value in five checked plots

\begin{tabular}{c|c|c|c|c|c}
\hline & HHT-1 & HHT-2 & HHT-3 & HHT-4 & HHT-5 \\
\hline $\mathrm{pH}$ & 8.57 & 8.66 & 8.46 & 8.36 & 8.09 \\
Electric conductivity & 6.05 & 4.92 & 10.6 & 5.21 & 3.65 \\
\hline
\end{tabular}




\section{Diversity of cultured bacteria by culture-dependent}

Cultured bacteria of five studied areas samples were isolated and purified in solid medium by culture-dependent methods, respectively. A total of 80 strains were isolated and purified from the plates that could grow steadily and fast in solid medium. Fortytwo strains were selected as the representative strains according to the morphological characteristics of the colonies and the Gram stains. However, Tian et al. (2016) isolated and purified 22 strains in Suaeda rhizosphere soil in Panjin delta. This circumstance may be partly due to the difference in sampling time and location, and may also be due to the different media used. In the present study, the selected 42 selected isolates were identified by $16 \mathrm{~S}$ rDNA sequence analysis (Table 2), which belonged to four phyla containing Actinobacteria 14.29\%, Bacteroidetes 4.76\%, Firmicutes 50\%, Proteobacteria $30.95 \%$. Forty-two isolates were divided into nine genera respectively, for example Agromyces, Arthrobacter, Kocuria, Pseudarthrobacter, Zhihengliuella, Cellulosimicrobium, Pontibacter, Myroides and Bacillus. Among nine genera, Bacillus and Pseudomonas were dominant genus.

\section{Diversity of uncultured bacteria by high-throughput sequencing}

Rarefaction curves of five samples were gradually towards flatness, and index reached saturation, which indicated that amount of sequencing data was reasonable and covered composition of flora in five samples (Fig. 1). Sequencing data represented microbe level of five samples, respectively. The number of unique operational taxonomic units (OTUs) (16S rRNA gene) represented the microbial species richness (Li et al., 2018). In this study, there were 184079 reads and 10154 OTUs at a cutoff of 97\% sequence similarity across all soil samples. The observed bacterial OTU numbers varied between 1854 and 2322 in samples of five studied areas (Table 3). The coverage frequency was $99.26 \%, 99.44 \%, 99.53 \%, 99.6 \%$ and $99.57 \%$, respectively. These showed that the information of microbial species in each region studied is basically fully reflected.

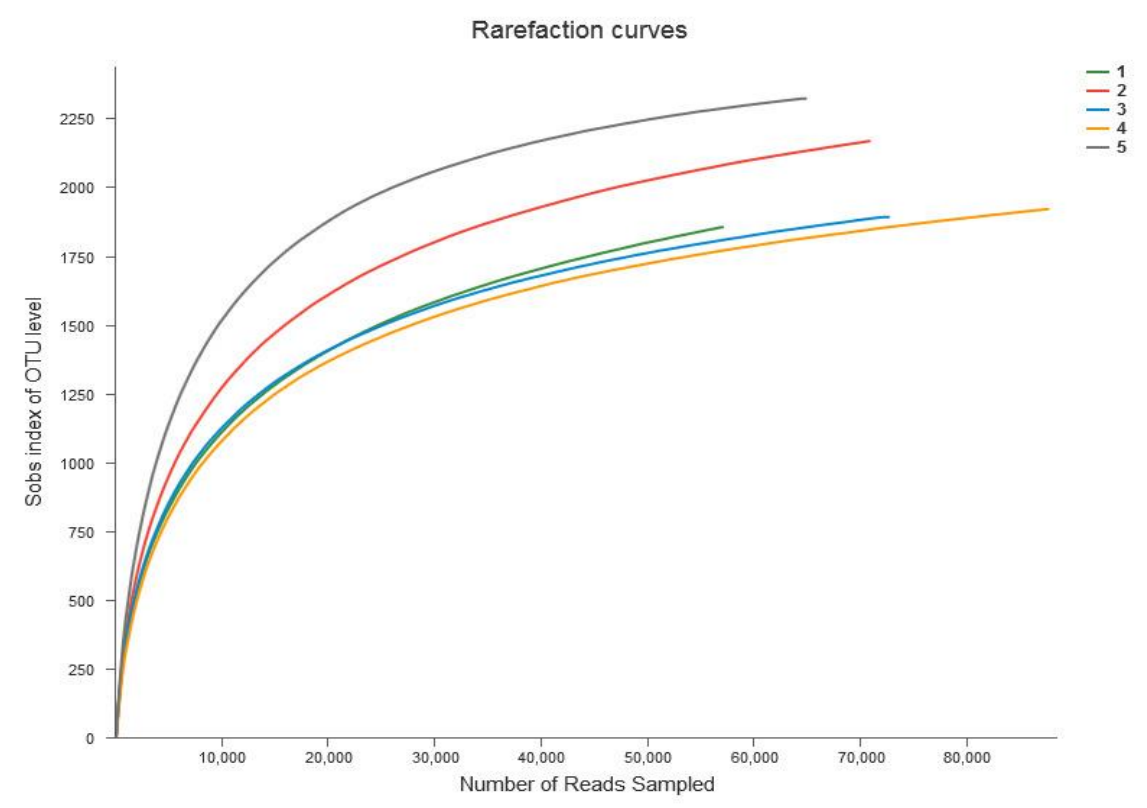

Figure 1. Rarefaction curves of five studied areas samples 
Table 2. Halophilic alkali bacteria cultured in five studied areas samples

\begin{tabular}{|c|c|c|c|}
\hline Name & Top-hit taxon & Accession No. & Similarity (\%) \\
\hline YJ1 & Bacillus siamensis & КСТC 13613 & 99.79 \\
\hline YJ2 & Bacillus megaterium & NBRC 15308 & 99.93 \\
\hline YJ3 & Cellulosimicrobium cellulans & LMG 16121 & 99.86 \\
\hline YJ4 & Bacillus altitudinis & $41 \mathrm{KF} 2 \mathrm{~b}$ & 100 \\
\hline YJ5 & Bacillus wiedmannii & FSL W8-0169 & 99.93 \\
\hline YJ7 & Bacillus paramycoides & $\mathrm{NH} 24 \mathrm{~A} 2(\mathrm{~T})$ & 99.67 \\
\hline YJ10 & Arthrobacter endophyticus & EGI 6500322 & 99.5 \\
\hline YJ14 & Bacillus aryabhattai & B8W22 & 100 \\
\hline YJ24 & Brevibacterium frigoritolerans & DSM 8801 & 99.37 \\
\hline YJ25 & Paenibacillus lautus & NRRL NRS-666 & 99.42 \\
\hline YJ26 & Acinetobacter johnsonii & CIP 64.6 & 98.89 \\
\hline YJ27 & Bacillus velezensis & CR-502 & 99.43 \\
\hline YJ29 & Sphingorhabdus marina & DSM 22363 & 98.37 \\
\hline YJ30 & Pseudomonas songnenensis & NEAU-ST5-5 & 99.5 \\
\hline YJ31 & Exiguobacterium marinum & DSM 16307 & 99.93 \\
\hline YJ33 & Bacillus aquimaris & КСТC 3903 & 98.83 \\
\hline YJ34 & Nitratireductor aquimarinus & CL-SC21 & 99.7 \\
\hline YJ35 & Sphingorhabdus marina & DSM 22363 & 97.4 \\
\hline YJ38 & Bacillus flexus & NBRC 15715 & 99.17 \\
\hline YJ39 & Myroides marinus & JS-08 & 99.42 \\
\hline YJ40 & Planococcus rifietoensis & M8 & 99.38 \\
\hline YJ42 & Bacillus crassostreae & JSM100118 & 100 \\
\hline YJ43 & Bacillus cereus & ATCC 14579 & 100 \\
\hline YJ44 & Photobacterium halotolerans & MACL01 & 99.25 \\
\hline YJ45 & Bacillus safensis & FO-36b & 100 \\
\hline YJ46 & Agromyces arachidis & AK-1 & 99.27 \\
\hline YJ48 & Halomonas heilongjiangensis & $9-2$ & 99.27 \\
\hline YJ49 & Bacillus litoralis & SW-211 & 99.31 \\
\hline YJ51 & Zhihengliuella halotolerans & YIM 70185 & 99.56 \\
\hline YJ52 & Bacillus idriensis & SMC 4352-2 & 99.43 \\
\hline YJ54 & Planococcus salinarum & DSM 23820 & 99.29 \\
\hline YJ55 & Arthrobacter subterraneus & $\mathrm{CH} 7$ & 99.21 \\
\hline YJ56 & Pontibacter odishensis & $\mathrm{JC} 130$ & 98.27 \\
\hline YJ61 & Erythrobacter citreus & $\mathrm{RE} 35 \mathrm{~F} / 1$ & 98.41 \\
\hline YJ63 & Pseudomonas linyingensis & LYBRD3-7 & 99.03 \\
\hline YJ64 & Pseudomonas kunmingensis & HL22-2 & 98.75 \\
\hline YJ65 & Pseudomonas zhaodongensis & NEAU-ST5-21 & 99.5 \\
\hline YJ66 & Kocuria polaris & CMS 76 & 98.74 \\
\hline YJ67 & Pseudarthrobacter oxydans & КCTC 3383 & 99.71 \\
\hline YJ68 & Bacillus zhangzhouensis & DW5-4 & 99.86 \\
\hline YJ71 & Exiguobacterium profundum & $10 \mathrm{C}$ & 99.93 \\
\hline YJ77 & Pseudomonas guineae & LMG 24016 & 99.07 \\
\hline YJ78 & Bacillus alkalisediminis & $\mathrm{K} 1-25$ & 99.36 \\
\hline
\end{tabular}


Table 3. Community indices of five samples

\begin{tabular}{c|c|c|c|c|c}
\hline Sample & reads & OTUs & Chao index & Shannon index & Coverage (\%) \\
\hline HHT1 & 32030 & 1854 & 2181 & 5.72 & 99.26 \\
HHT 2 & 40125 & 2167 & 2256 & 5.64 & 99.44 \\
HHT 3 & 36007 & 1891 & 2413 & 5.76 & 99.53 \\
HHT 4 & 38580 & 1920 & 2267 & 5.01 & 99.61 \\
HHT 5 & 37337 & 2322 & 2497 & 5.87 & 99.57 \\
\hline
\end{tabular}

The Chao and Shannon diversity index are the indicator of the abundance and an assessment of the diversity of bacteria in the biological environment, respectively (Chao, 1984; Shannon, 1948; Smalla, 2001). The index Chao across all soil samples was very high (Table 3). The index Chao of the HHT5 sample was the highest among them. However, the value of the HHT1 samples was the lowest, which indicated that the abundance was the lowest. The index Shannon of the HHT5 sample was the largest among them, which indicated that the diversity of bacteria was the most abundance.

There were mainly 13 phyla in five samples, which were Tenericutes, Spirochaetae, Latescibacteria, Verrucomicrobia, Planctomycetes, Cyanobacteria, Actinobacteria, Gemmationadetes, Chloroflexi, Acidobacteria, Firmicutes, Bacteroidetes and Proteobacteria. The relative abundance of each category varied across the five samples. The relative abundance of Proteobacteria of HHT1 sample was the highest among five samples, which reached $48.03 \%$. Firmicutes was also the widely distributed bacterial phylum in the other four studied samples, but it was completely missing in the HHT5 sample (Fig. 2A). The dominant phyla across soil samples were Proteobacteria (from 33.54 to $48.03 \%$ in five studied samples) and Bacteroidets (from 16.6 to $32.3 \%$ in five studied samples), which were consistent with the observation of Tian et al. (2016). The Aliifodinibius was the most abundant genus in all the samples accounting for $41.06 \%$, $44.57 \%, 37.78 \%, 31.06 \%$ and 36.9\%, respectively, followed by Gillisia and Bacillus. And, there were many bacteria unidentified in genus level in five samples (Fig. 2B).

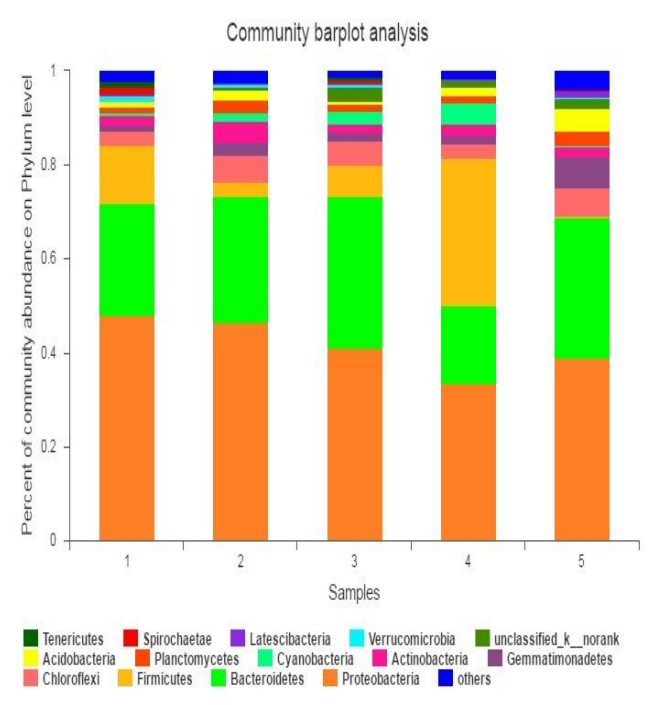

A

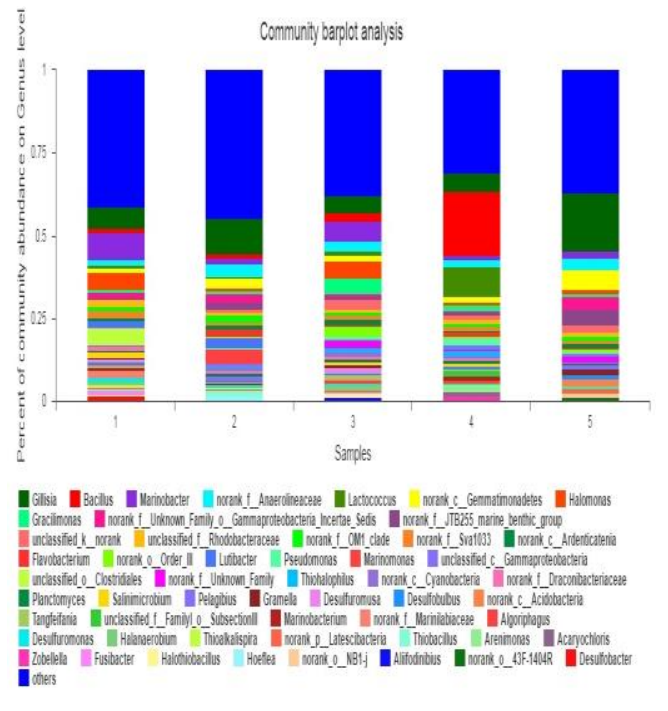

B

Figure 2. Bacterial relative abundance of five studied areas samples in phylum (A) and genus

(B) level 
In comparison with the culture-dependent methods, more bacteria were observed by high-throughput sequencing in phylum. Only four phyla bacteria were isolated by culture-dependent methods. However, there were 13 phyla, and more Chloroflexi bacteria of five studied areas samples and Gemmationadetes bacteria of HHT5 sample were observed by high-throughput sequencing (Fig. 2A), but these bacteria were not isolated by the culture-dependent methods (Table 2). Maybe, a special medium is needed to thrive for those bacteria. Therefore, the media suitable for saline-alkali environment should be developed to isolate species or strains that are best adapted to grow in saline-alkali soil.

\section{Conclusion}

The soil of five geographical regions studied is saline-alkali soil. By cultivable methods, 42 bacteria selected to identify by $16 \mathrm{~S}$ rDNA belonged to nine genus and four phyla. Bacillus and Planococcus was the dominant genus. Through the high-throughput sequencing in five studied areas samples, bacterial community was mainly composed of 13 phyla, which were Tenericutes, Spirochaetae, Latescibacteria, Verrucomicrobia, Planctomycetes, Cyanobacteria, Actinobacteria, Gemmationadetes, Chloroflexi, Acidobacteria, Firmicutes, Bacteroidetes and Proteobacteria. Therefore, the bacterial diversity was very rich in Panjin Red Beach. The bacteria strains should further be explored for agricultural and industrial use.

Acknowledgments. This work was supported by the National Natural Science Foundation of China (31600314), the Education Department of Liaoning Province fundamental project (LJC201912, LZD201901), Major incubating project of Shenyang Normal University (ZD201705) and Liaoning Province Science and Technology Plan Project (No.2017208001).

\section{REFERENCES}

[1] Bever, J. D., Platt, T. G., Morton, E. R. (2012): Microbial population and community dynamics on plant roots and their feedbacks on plant communities. - Annu Rev Microbiol 66: 265-283.

[2] Chao, A. (1984): Nonparametric estimation of the number of classes in a population. Scand J Stat 11: 265-270.

[3] Chistoserdova, L. (2010): Recent progress and new challenges in metagenomics for biotechnology. - Biotechnol Lett 32(10): 1351-1359.

[4] Herlemann, D. P., Labrenz, M., Jürgens, K., Bertilsson, S., Waniek, J. J., Andersson, A. F. (2011): Transitions in bacterial communities along the $2000 \mathrm{~km}$ salinity gradient of the Baltic Sea. - ISME J 5(10): 1571-1579.

[5] Horikoshi, K. (1999): Alkaliphiles: some applications of their products for biotechnology. - Microbiol Mol Biol Rev 63(4): 735-750.

[6] Li, H., Xu, Z. W., Yan, Q. Y., Yang, S., Van Nostrand, J. D., Wang, Z. R., He, Z. L., Zhou, J. Z., Jiang, Y., Deng, Y. (2018): Soil microbial beta-diversity is linked with compositional variation in aboveground plant biomass in a semi-arid grassland. - Plant Soil 423: 465-480.

[7] Liu, G. X., Hu, C. Q., Zhang, J. B., Shen, Y. P. (2001): Microbial communities in permafrost of the Tibetan Plateau and their significance. - J Glaciol Geocryol 23(4): 419422 (in Chinese). 
[8] Margesin, R., Schinner, F. (2001): Potential of halotolerant and halophilic microorganisms for biotechnology. - Extremophiles 5(2): 73-83.

[9] Olson, G. J., Brierley, J. A., Brierley, C. L. (2003): Bioleaching review part B: progress in bioleaching: applications of microbial processes by the minerals industries. - Appl Microbiol Biotech 63(3): 249-257.

[10] Passalacqua, K. D., Varadarajan, A., Ondov, B. D., Okou, D. T., Zwick, M. E., Bergman, N. H. (2009): Structure and complexity of a bacterial transcriptome. - J Bacteriol 191(10): 3203-3211.

[11] Rietz, D. N., Haynes, R. J. (2003): Effects of irrigation-induced salinity and sodicity on soil microbial activity. - Soil Biol Biochem 35(6): 845-854.

[12] Rinke, C., Schwientek, P., Sczyrba, A., Ivanova, N. N., Anderson, I. J., Cheng, J. F., Darling, A., Malfatti, S., Swan, B. K., Gies, E. A., Dodsworth, J. A., Hedlund, B. P., Tsiamis, G., Sievert, S. M., Liu, W. T., Eisen, J. A., Hallam, S. J., Kyrpides, N. C., Stepanauskas, R., Rubin, E. M., Hugenholtz, P., Woyke, T. (2013): Insights into the phylogeny and coding potential of microbial dark matter. - Nature 499(7459): 431-437.

[13] Shannon, C. E. (1948): A mathematical theory of communication. - Bell Syst Tech J 27: 379-423 and 623-656.

[14] Shen, P., Fan, X. R., Li, G. W. (2006): Microbiology Experiment. - Higher Education Press, Beijing, pp. 50-54 (in Chinese).

[15] Shi, W., Takano, T., Liu, S. K. (2012): Isolation and characterization of novel bacterial taxa from extreme alkali-saline soil. - World J Microbiol Biotechnol 28: 2147-2157.

[16] Smalla, K., Wieland, G., Buchner, A., Zock, A., Parzy, J., Kaiser, S., Roskot, N., Heuer, H., Berg, G. (2001): Bulk and rhizosphere soil bacterial communities studied by denaturing gradient gel electrophoresis: plant-dependent enrichment and seasonal shifts revealed. - Appl Environ Microbial 67(10): 4742-4751.

[17] Stetter, K. O., Fiah, G., Huber, G., Huber, R., Segerer, A. (1990): Hyperthermophilic microorganisms. - FEMS Microbiol Rev 75: 117-124.

[18] Theron, J., Cloete, T. E. (2000): Molecular techniques for determining microbial diversity and community structure in natural environments. - Crit Rev Microbiol 26(1): 37-57.

[19] Tian, R., Yu, Z. C., Li, Z. Y., Wang, X. L., Wang, B. (2016): Diversity of endophytic and rhizospheric bacteria of Suaeda heteroptera Kitag from Panjin Delta in Liaoning Province. - Microbiol China 43(07): 1462-1472 (in Chinese).

[20] Vanwonterghem, I., Jensen, P. D., Ho, D. P., Batstone, D. J., Tyson, G. W. (2014): Linking microbial community structure, interactions and function in anaerobic digesters using new molecular techniques. - Curr Opin Biotech 27: 55-64.

[21] Xia, W. W., Zhang, C. X., Zeng, X. W., Feng, Y. Z., Weng, J. H., Lin, X. G., Zhu, J. G., Xiong, Z. Q., Xu, J., Cai, Z. C., Jia, Z. J. (2011): Autotrophic growth of nitrifying community in an agricultural soil. - ISME J 5(7): 1226-1236.

[22] Zahran, H. H. (1997): Diversity, adaptation and activity of the bacterial flora in saline environments. - Biol Fertil Soils 25(3): 211-223.

[23] Zettler, L. A. A., Gómez, F., Zettler, E., Keenan, B. G., Amils, R., Sogin, M. L. (2002): Eukaryotic diversity in Spain's River of Fire. - Nature 417: 137.

[24] Zhao, Y., Yu, F., Guo, M. M., Bu, N. (2015): Isolation, identification and growthpromoting effect of Suaeda salsa endophyte fungus JP3. - J Shenyang Norm Univ 33: 116-120 (in Chinese). 